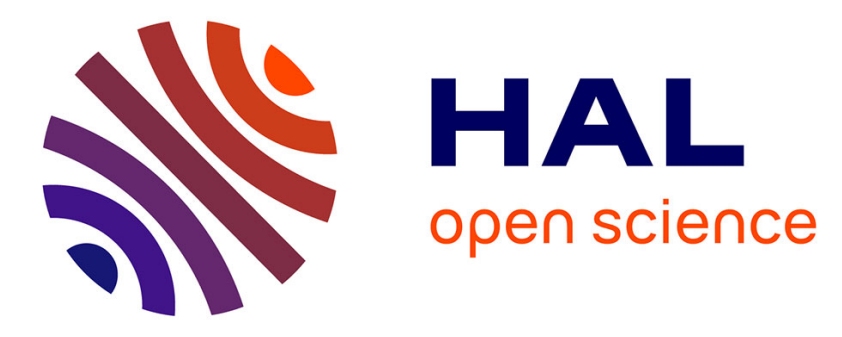

\title{
Estimation of spinopelvic muscles' volumes in young asymptomatic subjects: a quantitative analysis.
}

Célia Amabile, Bertrand Moal, Oussama Arous Chatara, Hélène Pillet, Jose G. Raya, Antoine Iannessi, Wafa Skalli, Virginie Lafage, Nicolas Bronsard

\section{To cite this version:}

Célia Amabile, Bertrand Moal, Oussama Arous Chatara, Hélène Pillet, Jose G. Raya, et al.. Estimation of spinopelvic muscles' volumes in young asymptomatic subjects: a quantitative analysis.. Surgical and Radiologic Anatomy, 2017, 39 (4), pp.393-403. 10.1007/s00276-016-1742-6 . hal-02460927

\section{HAL Id: hal-02460927 https://hal.science/hal-02460927}

Submitted on 30 Jan 2020

HAL is a multi-disciplinary open access archive for the deposit and dissemination of scientific research documents, whether they are published or not. The documents may come from teaching and research institutions in France or abroad, or from public or private research centers.
L'archive ouverte pluridisciplinaire HAL, est destinée au dépôt et à la diffusion de documents scientifiques de niveau recherche, publiés ou non, émanant des établissements d'enseignement et de recherche français ou étrangers, des laboratoires publics ou privés. 


\title{
Estimation of spinopelvic muscles' volumes in young asymptomatic subjects: a quantitative analysis
}

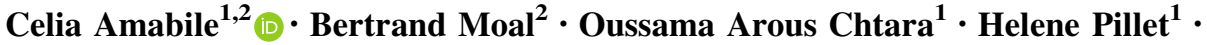 \\ Jose G. Raya ${ }^{3}$ - Antoine Iannessi ${ }^{4}$ - Wafa Skalli ${ }^{1}$ - Virginie Lafage ${ }^{2}$. \\ Nicolas Bronsard ${ }^{5}$
}

\begin{abstract}
Purpose Muscles have been proved to be a major component in postural regulation during pathological evolution or aging. Particularly, spinopelvic muscles are recruited for compensatory mechanisms such as pelvic retroversion, or knee flexion. Change in muscles' volume could, therefore, be a marker of greater postural degradation. Yet, it is difficult to interpret spinopelvic muscular degradation as there are few reported values for young asymptomatic adults to compare to. The objective was to provide such reference values on spinopelvic muscles. A model predicting the muscular volume from reduced set of MRI segmented images was investigated.

Methods A total of 23 asymptomatic subjects younger than 24 years old underwent an MRI acquisition from T12 to the knee. Spinopelvic muscles were segmented to obtain an accurate $3 \mathrm{D}$ reconstruction, allowing precise computation of muscle's volume. A model computing the volume of
\end{abstract}

muscular groups from less than six MRI segmented slices was investigated.

Results Baseline values have been reported in tables. For all muscles, invariance was found for the shape factor [ratio of volume over (area times length): $\mathrm{SD}<0.04$ ] and volume ratio over total volume $(\mathrm{SD}<1.2 \%)$. A model computing the muscular volume from a combination of two to five slices has been evaluated. The five-slices model prediction error (in $\%$ of the real volume from 3D reconstruction) ranged from $6 \%$ (knee flexors and extensors and spine flexors) to $11 \%$ (spine extensors).

Conclusion Spinopelvic muscles' values for a reference population have been reported. A new model predicting the muscles' volumes from a reduced set of MRI slices is proposed. While this model still needs to be validated on other populations, the current study appears promising for clinical use to determine, quantitatively, the muscular degradation. 
Keywords Muscles · MRI · Volume · Asymptomatic subjects · Young

\section{Introduction}

While skeletal postural alignment has been widely investigated based on X-ray analysis [3], quantification of the muscles' degradation is not yet fully documented. As muscular degradation (mainly in terms of decrease of crosssectional area) has been correlated to back pain $[12,18,29$, $31]$ and to aging $[1,10,36,37]$, there is a need for quantitative analysis of muscular system in relation to skeleton aging (bone quality degradation and postural alignment modifications). As a first step, to differentiate pathological changes in the muscular system from the one associated with aging; it is of primary importance to review reference values for young asymptomatic adults. However, the literature lacks descriptive values (especially on volumes) of the muscular system, specifically on the L1 to knee area, particularly involved in compensatory mechanisms.

Muscles' geometry has been explored using computed tomography (CT) [6, 31]. However, CT involves a significant ionizing dose: covering a specific part of the body extensively (significant number of slices) involves a moderate- to high radiation dose for the patient $[1.5 \mathrm{mSv}$ for a lumbar spine CT vs $0.02 \mathrm{mSv}$ for a chest X-ray (Food and Drug Administration, 2015)]. Most frequently, for CT, to avoid repeated acquisitions, only a reduced set of slices is acquired, only at specific locations of interest $[6,31]$.

Another method used to investigate muscles is the ultrasound (non-invasive). However, deep muscles can be more difficult to explore as it is a surface technique, and studies mainly focused on dynamic (muscles' contraction) [28, 34].

Finally, the most common imaging modality for the analysis of the muscular system is the MRI [5, 8, 9, 12, 17, 18, 27, 29, 30, 33, 36]. For example, different studies conducted by Fortin et al. reported CSA values and fat infiltration quantification [7-9] on various populations. Particularly, these studies provided valuable insights on the relation between muscular asymmetry, fat infiltration and low back pain [7]. Most of the studies focusing on muscular investigation from MRI images, reported only 2D parameters such as cross-sectional area [9, 12, 19, 27, 29, 30, 33, 36], and/or information on fat infiltration of muscles considered [5, 7, 9, 17, 19, 29, 30, 38]. Muscular volume has been, however, reported for the quadriceps femoris components [2], pelvic and/or lower limb muscles $[4,13,22]$. The three last studies either included only a limited number of subjects ( 3 females and 3 males [22], or a wide range of age in the population considered (from 12 to 51 years old [13]), or lastly, focused on the effect of bed-resting [4] (thus, not considering daily representative condition). While fat infiltration gives an insight on the muscle quality [7,9], calibration may be an issue and this study focuses on the volume computation and 3D geometrical parameters of the muscles only.

Computing muscular volume can be done by interpolation or by 3D reconstruction of the muscle. In particular, MRI-based 3D reconstruction and volume computation method has been reported as accurate [15] and repeatable [25]. Still, quantitative analysis of MRI images can be time-consuming. The deformation of a parametric specific object (DPSO) method $[15,16]$ allows for an accurate and precise 3D reconstruction of individual muscles, from segmentation on a selected set of MRI images, leading to an accurate volume computation in a fairly reduced amount of time. This method had been used on adults with spinal deformities for the spinopelvic area [25] and on volunteers younger than 40 years old, for the cervical spine [20] and for lower limbs $[14,35]$. While DPSO method provides time reduction by reducing the number of slices to consider per muscle, this method involves different slices for each muscle which may still be long when numerous muscles are considered. In addition to characterizing spinopelvic muscles' 3D geometry (cross-sectional area as well as volume), on young asymptomatic volunteers, our aim is to propose a model quantifying rapidly muscular groups' volume from less than six MRI segmented images for all muscles.

\section{Methods}

\section{Study design}

This is a prospective, single-center study, recruiting subjects from September 2014 to March 2015. All participants signed an informed consent prior enrollment. This study has been reviewed and approved by Comité de Protection des Personnes (CPP 14.013), and included asymptomatic adults younger than 24 years old. Exclusion criteria included: previous surgery on lower limbs or spine, pregnancy, postural disorder, MRI contraindication (mainly linked to magnetic field).

\section{Data collection}

Information collected included: age, body mass index (BMI), and sex. History of musculoskeletal injury was also documented. Each subject undertook an MRI exam (General Electric 1.5T, Fairfield, USA), collecting axial images from vertebra T12 to the patella distal insertion. The protocol used was the same as the one described in a previous study [24]. The MRI machine was set with the following parameters: $\mathrm{TR} / \mathrm{TE}=427 / 11.3 \mathrm{~ms}$, acquisition matrix $=416 \times 416$ 
pixels, phase oversampling $=100 \%$, in-plane resolution $=0.82 \times 0.82 \mathrm{~mm}^{2}, 8$ stages, 40 slices by stage, slice thickness $=5 \mathrm{~mm}$, slice gap $=0 \mathrm{~mm}$, flip angle $=160^{\circ}$, parallel imaging acceleration factor (iPat) $=2, \quad$ bandwidth $=391 \mathrm{~Hz} /$ pixel, echo spacing $=11.3 \mathrm{~ms}$, acquisition time per stage $=7 \mathrm{~min}$, and total acquisition time $=50 \mathrm{~min}$.

$3 \mathrm{D}$ reconstruction of the muscles (with information from all MRI slices) was carried out with software developed in our institution, using the DPSO method [15, 25]. Muscles of interest are represented in Fig. 1; analysis was performed for the left and right muscles.

Because the border between specific muscles can be challenging to identify, some muscles were segmented together:

- the "adductor" includes the adductor brevis, the adductor longus, the adductor magnus as well as the obturatorius internus and the pectineus,

- the "erector spinae" includes the tractus medialis (multifidus and interspinales) and lateralis (longissimus and iliocostalis),

- the "iliopsoas" includes the iliacus and the psoas,

- the "vastus lateralis inter" includes the vastus lateralis and vastus intermedius.

For each muscle, the following geometric parameters were computed: length of the muscle $(L)$, maximal anatomical cross-sectional area $\left(A_{\max }\right)$ and volume of the muscle normalized (divided) by the height of the subject $\left(V_{\text {normH }}\right)$.

\section{Statistical analysis}

Normality of each parameter studied ( $\left.V_{\text {normH }}, L, S_{p}, A_{\max }\right)$, for individual muscle, was tested with a Lilliefors test [21]. For each muscle, differences were investigated between right and left sides and between females and males, for the geometric parameters $\left(V_{\text {normH }}, L, A_{\max }\right)$ : using a $T$ test if it was found to be drawn from a normal distribution; using a Mann-Whitney test otherwise. For each side (right and left), the ratio $\left(R V_{\text {tot }}\right)$ of each muscle's volume over the total muscle of the side was computed as well. For $R V_{\text {tot }}$, mean, standard deviation (SD) and coefficient of variation $(\mathrm{CV})$ [SD $\times 100 /$ Mean] have been calculated.

In the following, muscles were grouped in functional groups per joint, respectively, as flexors and extensors of the spine, hip and knee as detailed in Fig. 1. For each group, the total muscular volume $\left(V^{\mathrm{gp}}\right)$ was computed. Also, for each joint studied (knee, spine, hip), the ratio of flexors over extensors, $R_{\mathrm{flex} / \mathrm{ext}}$, was computed as the volume ratio of flexors over extensors muscles of the joint. Normality of $V^{\mathrm{gp}}$ and $R_{\mathrm{flex} / \mathrm{ext}}$ was tested with a Lilliefors test. Level of significance, for all statistical tests, was set to 0.05 .

\section{Alternative estimations of the muscular volume}

Two methods were studied to estimate, more rapidly, the muscular volume in a clinical environment: maximal section method and reduced MRI set method.

\section{Maximal section method}

As described in Mersmann's study on the lower leg muscles [23], the volume of each muscle was computed from the length and maximal cross-sectional area of the muscle, using a factor of shape $S_{\mathrm{p}}$. This factor was computed as the ratio of the volume $(V)$ over the product [muscle length by muscle's maximal sectional area]: $S_{p}=V /\left(L \times A_{\max }\right)$. Validation of this factor of shape was done with a leaveone-out method.

\section{Reduced MRI set method}

Estimation of the volume from a reduced set of MRI segmented slices was investigated to reduce segmentation time and offer a tool applicable in a clinical setting. To quantify muscular volume more rapidly, a model using the DPSO method [16, 25], with less than six segmented slices was investigated.

The volumes of all functional groups were predicted from a multilinear regression using information of a limited number of slices (from two to five slices). The following predictors were used in the model: age, BMI, femoral length and the sum of the areas of the muscles contained in the group considered, on the slice considered. A principal component analysis (PCA) was performed to retain only relevant predictors (linear combination of the initially considered predictors). Each computed PCA predictor was replaced by the initial predictor most correlated with it, to obtain a clear and understandable prediction equation. Even if the sum of the areas of the muscles was not retained by this procedure as a predictor, it was added as such for its relevance as a global indicator.

The model was built on data from right side of the subjects. The slices were numbered upward from 0 to 150 : slice 0 as the first slice with the posterior part of the femoral condyles visible, and slice 100 as the last slice with the femoral head visible.

The spine flexors' $\left(\right.$ Spine $_{\text {flex }}$ ) and spine extensors' $\left(\right.$ Spine $\left._{\text {ext }}\right)$ muscles were segmented on slices from T12 to the greater trochanter ("proximal slices"), while the knee

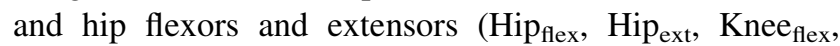
Knee $_{\text {ext }}$ ) were segmented on slices from S1 to the femoral 


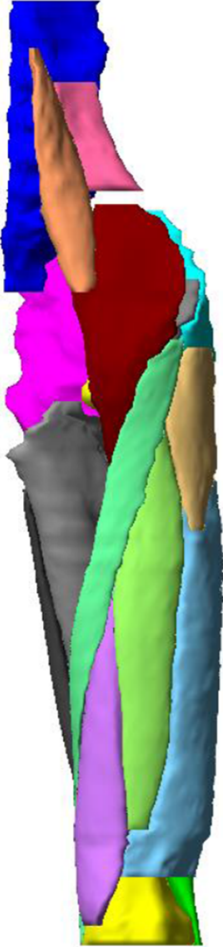

(A)

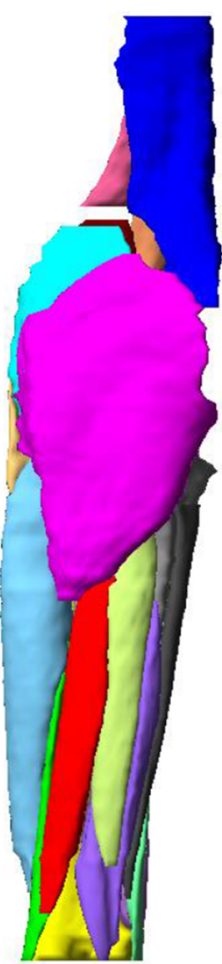

(B)

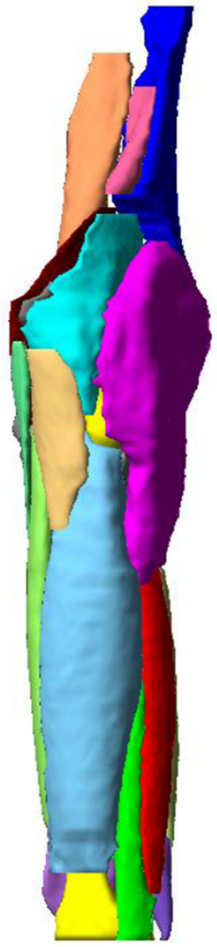

(C)

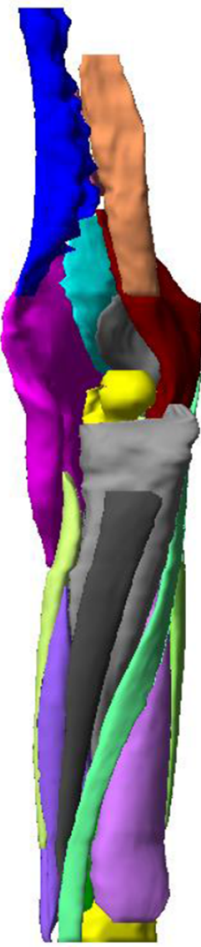

(D)

\begin{tabular}{|c|c|c|c|c|c|c|}
\hline \multirow[b]{2}{*}{$F:$ flexors / E: extensors } & \multicolumn{2}{|c|}{ Spine } & \multicolumn{2}{|c|}{ Hip } & \multicolumn{2}{|c|}{ Knee } \\
\hline & $\mathbf{F}$ & $\mathrm{E}$ & $\mathbf{F}$ & E & F & $\mathrm{E}$ \\
\hline Adductor & & & $X$ & & & \\
\hline Biceps femoris longum & & & & $x$ & $X$ & \\
\hline Biceps femoris breve & & & & $X$ & $X$ & \\
\hline Erectus spinae & & $X$ & & & & \\
\hline Femur & & & & & & \\
\hline Gluteus maximus & & & & X & & \\
\hline Gluteus medius & & & & & & \\
\hline Gluteus minimus & & & & & & \\
\hline Gracilis & & & $X$ & & $X$ & \\
\hline Iliacus & $X$ & & $X$ & & & \\
\hline Psoas & X & & $X$ & & & \\
\hline Quadratus lumborum & & $X$ & & & & \\
\hline Rectus femoris & & & X & & & $x$ \\
\hline Sartorius & & & X & & $X$ & \\
\hline Semimembranosus & & & & X & $X$ & \\
\hline Semitendinosus & & & & $X$ & $X$ & \\
\hline Tensor fasciae lata & & & $X$ & & & \\
\hline Vastus lateralis inter & & & & & & X \\
\hline Vastus medialis & & & & & & $x$ \\
\hline
\end{tabular}

for the analysis: spine flexors (Spine F), spine extensors (Spine E), hip flexors (Hip F), hip extensors (Hip E), knee flexors (Knee F) and knee extensors (Knee E)

$17.4-24.8 \mathrm{~kg} / \mathrm{m}^{2}$ ). Mean age was 19.3 years (SD: 0.8). Mean BMI was $20.9 \mathrm{~kg} / \mathrm{m}^{2}$ (SD: 2.0). Females' height ranged from 155 to 169 vs 171 to $185 \mathrm{~cm}$ for men.

\section{Statistical analysis}

Tables 1 and 2 present means and SD of $L, A_{\max }$, $S_{\mathrm{p}}, V_{\text {normH }}, V, \mathrm{RV}_{\text {tot }}$ and $\mathrm{CV}$ of $\mathrm{RV}_{\text {tot. }}$. No significant difference was found between right/left side parameters ( $V_{\text {normH }}, V, L, A_{\max }$ ), except for the following: $V, V_{\text {normH }}$ and $\mathrm{RV}_{\text {tot }}$ of the quadratus lumborum, rectus femoris and semitendinosus; $L$ of the gluteus maximus, and $A_{\max }$ of quadratus lumborum, adductor and semitendinosus. Difference between right and left sides for these muscles/parameters was, in average, less than $11 \%$ of the mean value right/left (Tables 1, 2). Values were averaged right/left when no significant difference was found (Tables 1,2).

The major part of the geometrical parameters considered followed a normal distribution except for the following muscles and parameters: for example, the $V_{\text {normH }}$ of right iliopsoas, the $V$ of right adductor, the $L$ of left erectus spinae, the $A_{\max }$ of right gluteus minimus, the $\mathrm{RV}_{\text {tot }}$ of left sartorius or the $S_{\mathrm{p}}$ of both sides of quadratus

lumborum.
The sample studied included 12 females and 11 males. Age (respectively, BMI) ranged from 18 to 21 years (resp. 
Table 1 Means, standard deviations $(1 \times \mathrm{SD})$ and coefficient of variation $(\mathrm{CV}=\mathrm{SD} \times 100 / \mathrm{mean})$ of volume $(V)$, volume normalized by height $\left(V_{\mathrm{H}}\right)$, and volumic ratio $\left(\mathrm{RV}_{\text {tot }}\right)$ for females and males

\begin{tabular}{|c|c|c|c|c|c|c|c|c|c|c|c|c|c|c|}
\hline & \multicolumn{4}{|c|}{$V\left(\mathrm{~cm}^{3}\right)$} & \multicolumn{4}{|c|}{$V_{\text {normH }}\left(\mathrm{cm}^{2}\right)$} & \multicolumn{6}{|c|}{$\mathrm{RV}_{\text {tot }}(\%)$} \\
\hline & \multicolumn{2}{|c|}{ Females } & \multicolumn{2}{|l|}{ Males } & \multicolumn{2}{|c|}{ Females } & \multicolumn{2}{|l|}{ Males } & \multicolumn{3}{|c|}{ Females } & \multicolumn{3}{|l|}{ Males } \\
\hline & Mean & SD & Mean & SD & Mean & SD & Mean & SD & Mean & SD & $\mathrm{CV}$ & Mean & SD & $\mathrm{CV}$ \\
\hline Iliopsoas $^{\mathrm{ab}}$ & 290.9 & 36.2 & 514.8 & 43.6 & 1.8 & 0.2 & 2.9 & 0.3 & 6.9 & 0.6 & 8.6 & 8.2 & 0.5 & 5.8 \\
\hline \multicolumn{15}{|l|}{ Quadratus lumborum ${ }^{\mathrm{b}}$} \\
\hline $\mathrm{R}$ & 33.7 & 9.2 & 62.0 & 7.8 & 0.2 & 0.1 & 0.3 & 0.0 & 0.8 & 0.2 & 22.2 & 1.0 & 0.1 & 12.7 \\
\hline $\mathrm{L}$ & 35.9 & 7.8 & 67.8 & 9.8 & 0.2 & 0.0 & 0.4 & 0.1 & 0.8 & 0.1 & 15.4 & 1.1 & 0.2 & 15.7 \\
\hline Erectus spinae & 294.5 & 42.9 & 419.2 & 55.7 & 1.8 & 0.3 & 2.3 & 0.3 & 7.0 & 0.8 & 11.8 & 6.7 & 0.8 & 12.3 \\
\hline Gluteus maximus ${ }^{\mathrm{a}}$ & 606.1 & 80.4 & 829.2 & 97.0 & 3.7 & 0.5 & 4.6 & 0.5 & 14.4 & 1.1 & 7.9 & 13.2 & 1.0 & 7.5 \\
\hline Gluteus medius & 236.5 & 28.9 & 341.1 & 36.3 & 1.4 & 0.2 & 1.9 & 0.2 & 5.6 & 0.4 & 7.1 & 5.5 & 0.6 & 11.4 \\
\hline Gluteus minimus & 76.2 & 7.8 & 107.8 & 20.2 & 0.5 & 0.1 & 0.6 & 0.1 & 1.8 & 0.3 & 15.2 & 1.7 & 0.3 & 14.9 \\
\hline Adductor & 663.0 & 85.5 & 1028.5 & 81.6 & 4.1 & 0.5 & 5.8 & 0.5 & 15.7 & 1.2 & 7.4 & 16.4 & 0.7 & 4.3 \\
\hline Vastus lateralis inter & 824.9 & 93.2 & 1178.6 & 85.9 & 5.0 & 0.6 & 6.6 & 0.5 & 19.6 & 1.1 & 5.5 & 18.8 & 0.6 & 3.4 \\
\hline Vastus medialis & 314.9 & 37.4 & 465.1 & 49.3 & 1.9 & 0.2 & 2.6 & 0.3 & 7.5 & 0.6 & 7.9 & 7.4 & 0.7 & 9.4 \\
\hline Tensor fasciae lata & 45.8 & 10.6 & 69.8 & 21.8 & 0.3 & 0.1 & 0.4 & 0.1 & 1.1 & 0.2 & 21.5 & 1.1 & 0.3 & 28.8 \\
\hline \multicolumn{15}{|l|}{ Rectus femoris } \\
\hline $\mathrm{R}$ & 190.4 & 26.0 & 280.0 & 24.8 & 1.2 & 0.2 & 1.6 & 0.1 & 4.5 & 0.4 & 9.0 & 4.5 & 0.4 & 9.0 \\
\hline $\mathrm{L}$ & 187.4 & 28.2 & 267.5 & 24.2 & 1.1 & 0.2 & 1.5 & 0.1 & 4.4 & 0.4 & 9.7 & 4.3 & 0.3 & 7.9 \\
\hline Gracilis & 66.5 & 9.8 & 104.8 & 18.3 & 0.4 & 0.1 & 0.6 & 0.1 & 1.6 & 0.2 & 12.5 & 1.7 & 0.2 & 13.4 \\
\hline Sartorius & 100.3 & 17.5 & 161.8 & 24.1 & 0.6 & 0.1 & 0.9 & 0.1 & 2.4 & 0.3 & 12.5 & 2.6 & 0.3 & 10.7 \\
\hline \multicolumn{15}{|l|}{ Biceps femoris breve ${ }^{a}$} \\
\hline $\mathrm{R}$ & 60.5 & 11.5 & 112.8 & 25.0 & 0.4 & 0.1 & 0.6 & 0.1 & 1.5 & 0.2 & 15.2 & 1.8 & 0.3 & 19.7 \\
\hline $\mathrm{L}$ & 63.2 & 14.1 & 107.9 & 20.6 & 0.4 & 0.1 & 0.6 & 0.1 & & & & & & \\
\hline Biceps femoris longum & 128.1 & 17.9 & 184.1 & 23.8 & 0.8 & 0.1 & 1.0 & 0.1 & 3.0 & 0.3 & 9.6 & 2.9 & 0.3 & 10.1 \\
\hline Semimembranosus & 154.2 & 22.6 & 223.4 & 31.7 & 0.9 & 0.1 & 1.2 & 0.2 & 3.7 & 0.4 & 12.1 & 3.6 & 0.4 & 12.2 \\
\hline \multicolumn{15}{|l|}{ Semitendinosus } \\
\hline $\mathrm{R}$ & 129.4 & 24.6 & 196.0 & 24.3 & 0.8 & 0.1 & 1.1 & 0.1 & 3.1 & 0.5 & 16.5 & 3.1 & 0.3 & 9.9 \\
\hline $\mathrm{L}$ & 124.2 & 26.3 & 183.5 & 20.2 & 0.8 & 0.2 & 1.0 & 0.1 & 2.9 & 0.4 & 15.1 & 2.9 & 0.2 & 6.8 \\
\hline
\end{tabular}

Values were averaged over right and left sides when no significant difference was found. Males' and females' values were separated as significant differences were found for all muscles for $(V)$ and $V_{\mathrm{H}}$

$a^{a}$ (respectively ${ }^{b}$ ) means that statistical differences between males and females were found for $R V_{\text {tot }}$, for the right side of the muscle (respectively, for the left side of the muscle)

Statistical differences between right/left $S_{\mathrm{p}}$ were found for specific muscles, for which the difference was less than $3 \%$ of the mean value right/left (Table 2).

Statistical differences between sexes were found for all muscles and femur, for $A_{\max }, V, V_{\text {normH }}$ (overall greater values for males). Even when considering normalized volume by the subject's height $\left(V_{\text {normH }}\right)$, males present greater volumes than females: average 1.9 vs $1.4 \mathrm{~cm}^{2}$; range $0.3-6.6 \mathrm{~cm}^{2}$ vs $0.2-5.0 \mathrm{~cm}^{2}$. For $L$ (respectively, $\mathrm{RV}_{\text {tot }}$ ), significant differences were found between sexes for both sides for: gluteus maximus/medius, vastus lateralis inter, gracilis, sartorius, biceps femoris breve, semimembranosus, femur; for the right gluteus minimus and rectus femoris; and for the left vastus medialis, biceps femoris longum, and erectus spinae, (respectively, for both sides of the iliopsoas; for the right gluteus maximus and biceps femoris breve and for the left quadratus lumborum). No statistical differences between sexes were found for $S_{\mathrm{p}}$.

Ratio of a given muscle' volume over the total volume $\left(\mathrm{RV}_{\text {tot }}\right)$ was found as quasi-invariant for all muscles $(\mathrm{SD}<1.2 \%)$.

Table 3 presents means, $\mathrm{SD}$ and $\mathrm{CV}$ of muscular groups' volumes $V^{\text {gp }}$ and ratio of flexors vs extensors $R_{\mathrm{flex} / \mathrm{ext}}$. For each muscular functional group studied, for males and females separately, no statistical difference between right and left sides, was found for the volumes $V^{\text {gp }}$ ( $p>0.05$ for Student's $T$ test or Mann-Whitney test depending on normality of data). 
Table 2 Means and standard deviations $(1 \times \mathrm{SD})$ of length $(L)$, maximal axial cross-sectional area $\left(A_{\max }\right)$ and shape factor $\left(S_{\mathrm{p}}\right)$, for females and males

\begin{tabular}{|c|c|c|c|c|c|c|c|c|c|c|c|}
\hline & \multicolumn{4}{|l|}{$L(\mathrm{~cm})$} & \multicolumn{4}{|c|}{$A_{\max }\left(\mathrm{cm}^{2}\right)$} & \multicolumn{3}{|l|}{$S_{\mathrm{p}}$} \\
\hline & \multicolumn{2}{|l|}{$\mathrm{F}$} & \multicolumn{2}{|l|}{ M } & \multicolumn{2}{|l|}{$\mathrm{F}$} & \multicolumn{2}{|l|}{ M } & \multirow[t]{2}{*}{ Mean } & \multirow[t]{2}{*}{ SD } & \multirow[t]{2}{*}{ Root mean square error $(\%)$} \\
\hline & Mean & SD & Mean & SD & Mean & SD & Mean & SD & & & \\
\hline \multicolumn{12}{|l|}{ Quadratus lumborum } \\
\hline $\mathrm{R}$ & 13.1 & 2.3 & 13.6 & 2.1 & 5.8 & 1.2 & 8.8 & 1.4 & 0.49 & 0.04 & 17.7 \\
\hline $\mathrm{L}$ & & & & & 6.0 & 1.2 & 9.7 & 1.8 & & & \\
\hline Erectus spinae $^{\mathrm{b}}$ & 22.1 & 2.0 & 23.6 & 2.1 & 22.5 & 2.5 & 29.8 & 2.8 & 0.59 & 0.00 & 5.2 \\
\hline \multicolumn{12}{|l|}{ Gluteus maximus $^{\mathrm{ab}}$} \\
\hline $\mathrm{R}$ & 27.9 & 2.0 & 30.3 & 1.9 & 40.1 & 4.9 & 49.2 & 4.2 & 0.55 & 0.00 & 5.9 \\
\hline $\mathrm{L}$ & 26.9 & 1.6 & 30.3 & 1.5 & & & & & & & \\
\hline Gluteus medius $^{\mathrm{ab}}$ & 18.1 & 0.8 & 20.6 & 1.0 & 25.6 & 3.8 & 33.7 & 2.4 & 0.5 & 0.01 & 6.6 \\
\hline Gluteus minimus $^{\mathrm{a}}$ & 13.1 & 1.4 & 14.7 & 1.2 & 12.3 & 1.5 & 15.8 & 2.7 & 0.48 & 0.01 & 11.9 \\
\hline \multicolumn{12}{|l|}{ Adductor } \\
\hline $\mathrm{R}$ & 36.0 & 2.8 & 38.3 & 3.1 & 39.6 & 4.5 & 58.3 & 4.1 & 0.47 & 0.00 & 7.1 \\
\hline $\mathrm{L}$ & & & & & 39.2 & 5.0 & 55.8 & 3.9 & & & \\
\hline Vastus lateralis inter ${ }^{\mathrm{ab}}$ & 34.6 & 1.2 & 37.8 & 1.5 & 40.4 & 4.9 & 52.8 & 4.5 & 0.59 & 0.00 & 4.8 \\
\hline Vastus medialis ${ }^{\mathrm{b}}$ & 31.2 & 1.7 & 33.5 & 2.1 & 17.4 & 2.2 & 24.1 & 2.7 & 0.58 & 0.00 & 5.2 \\
\hline Tensor fasciae lata & 15.7 & 1.6 & 16.1 & 2.4 & 4.9 & 1.1 & 7.2 & 2.2 & 0.60 & 0.01 & 9.0 \\
\hline Rectus femoris $^{\mathrm{a}}$ & 31.1 & 2.1 & 33.3 & 1.7 & 10.6 & 1.6 & 14.2 & 1.6 & 0.58 & 0.00 & 4.6 \\
\hline Gracilis $^{\mathrm{ab}}$ & 31.0 & 2.7 & 33.8 & 2.5 & 3.4 & 0.6 & 4.7 & 0.8 & 0.65 & 0.01 & 5.0 \\
\hline Sartorius $^{\mathrm{ab}}$ & 46.5 & 1.4 & 50.8 & 2.1 & 2.8 & 0.5 & 4.1 & 0.6 & 0.77 & 0.00 & 4.7 \\
\hline Biceps femoris breve $\mathrm{e}^{\mathrm{ab}}$ & 21.5 & 1.9 & 24.5 & 2.0 & 5.0 & 0.8 & 8.2 & 1.5 & 0.57 & 0.01 & 8.8 \\
\hline Biceps femoris longum $^{\mathrm{b}}$ & 26.0 & 2.6 & 27.1 & 2.2 & 9.3 & 1.4 & 12.8 & 1.7 & 0.53 & 0.00 & 7.1 \\
\hline Semimembranosus ${ }^{\mathrm{ab}}$ & 26.1 & 1.6 & 28.4 & 1.1 & 10.1 & 1.6 & 13.0 & 2.0 & 0.60 & 0.01 & 6.7 \\
\hline \multicolumn{12}{|l|}{ Semitendinosus } \\
\hline $\mathrm{R}$ & 30.7 & 2.9 & 31.6 & 3.4 & 7.1 & 1.3 & 11.0 & 1.8 & 0.58 & 0.01 & 7.4 \\
\hline $\mathrm{L}$ & & & & & 7.0 & 1.8 & 10.1 & 1.2 & & & \\
\hline Femur $^{\mathrm{ab}}$ & 44.5 & 1.5 & 49.1 & 1.7 & 33.8 & 3.5 & 42.6 & 3.5 & - & - & - \\
\hline
\end{tabular}

Values were averaged over right and left sides when no significant difference was found for $L$ and $A_{\max }$. Males' and females' values were separated as significant differences were found for all muscles for $A_{\max } \cdot{ }^{a}$ (respectively ${ }^{b}$ ) means that statistical differences between males and females were found for $L$, for the right side of the muscle (respectively, for the left side of the muscle). For $S_{\mathrm{p}}$, values were averaged over sexes as no significant differences were found between males and females. Values were averaged and over right/left sides as when the difference was found statistically significant, the difference did not exceed $3 \%$ of the mean value. Root mean square error (RMS), between estimated volume (from average shape factor) and real volume in $\%$ of the real volume, was averaged over right and left RMS

\section{Alternative estimations of the muscular volume}

\section{Maximal section method}

Table 2 presents mean and SD of $S_{\mathrm{p}}$ for each muscle and the prediction error (RMS). For most muscles, the RMS was less than $10 \%$, except for gluteus minimus $(11.9 \%)$ and quadratus lumborum (17.7\%).

\section{Reduced MRI set method}

Figure 2 presents the best combination of slices. Single couple of slices, well chosen, at femoral and pelvic level, led to volume estimation with less than $15 \%$ of error. The five-slices model prediction error (in $\%$ of the real volume computed from 3D reconstruction) ranged from $6 \%$ $\left(\mathrm{Knee}_{\text {flex }}\right.$, Knee $\mathrm{ext}_{\text {and }}$ Spine flex $)$ to $11 \%\left(\right.$ Spine $\left._{\text {ext }}\right)$, this error being around 9-10\% for Hip flex and Hipext. Equations predicting the volume are presented in Tables 4 and 5 .

\section{Discussion}

This study reports reference values of muscular volume, length and cross-sectional areas for young asymptomatic subjects, providing baseline values for future studies and more additional findings. Ratio of a given muscle volume 
Table 3 Means; standard deviations (SD) and coefficient of variation $(\mathrm{CV}=\mathrm{SD} \times 100 /$ mean $)$ of functional groups' volume $\left(V^{\mathrm{gp}}\right)$ and functional groups' ratio of flexors/extensors $\left(R_{\mathrm{flex} / \mathrm{ext}}\right)$, for females and males, for right and left sides

\begin{tabular}{|c|c|c|c|c|c|c|}
\hline & \multicolumn{3}{|c|}{ Females } & \multicolumn{3}{|l|}{ Males } \\
\hline & Mean & SD & $\mathrm{CV}(\%)$ & Mean & SD & $\mathrm{CV}(\%)$ \\
\hline \multicolumn{7}{|c|}{ Volume $\left(\mathrm{cm}^{3}\right): V^{\mathrm{gp}}$} \\
\hline \multicolumn{7}{|c|}{ Spine flex } \\
\hline $\mathrm{R}$ & 287.4 & 38.0 & 13.2 & 518.4 & 49.0 & 9.5 \\
\hline $\mathrm{L}$ & 294.4 & 36.5 & 12.4 & 511.2 & 40.1 & 7.9 \\
\hline \multicolumn{7}{|c|}{ Spine ext } \\
\hline $\mathrm{R}$ & 328.1 & 48.2 & 14.7 & 482.5 & 53.7 & 11.1 \\
\hline $\mathrm{L}$ & 330.6 & 52.4 & 15.8 & 485.7 & 61.4 & 12.6 \\
\hline \multicolumn{7}{|c|}{ Hip flex } \\
\hline $\mathrm{R}$ & 1351.9 & 145.2 & 10.7 & 2176.7 & 160.6 & 7.4 \\
\hline $\mathrm{L}$ & 1358.7 & 154.9 & 11.4 & 2130.2 & 190.0 & 8.9 \\
\hline \multicolumn{7}{|c|}{ Hip ext } \\
\hline $\mathrm{R}$ & 1072.0 & 124.0 & 11.6 & 1538.0 & 138.8 & 9.0 \\
\hline $\mathrm{L}$ & 1082.1 & 128.0 & 11.8 & 1535.7 & 144.7 & 9.4 \\
\hline \multicolumn{7}{|c|}{ Knee flex } \\
\hline $\mathrm{R}$ & 636.1 & 76.6 & 12.0 & 980.3 & 96.1 & 9.8 \\
\hline $\mathrm{L}$ & 639.5 & 78.3 & 12.3 & 968.0 & 104.7 & 10.8 \\
\hline \multicolumn{7}{|c|}{ Knee ext } \\
\hline $\mathrm{R}$ & 1319.7 & 138.8 & 10.5 & 1927.1 & 162.0 & 8.4 \\
\hline $\mathrm{L}$ & 1337.6 & 163.0 & 12.2 & 1907.8 & 103.0 & 5.4 \\
\hline \multicolumn{7}{|c|}{ Ratio of flexors over extensors: $R_{\text {flex_ext }}$} \\
\hline \multicolumn{7}{|c|}{ Spine } \\
\hline $\mathrm{R}$ & 0.9 & 0.1 & 15.7 & 1.1 & 0.1 & 13.2 \\
\hline $\mathrm{L}$ & 0.9 & 0.2 & 16.8 & 1.1 & 0.1 & 12.8 \\
\hline \multicolumn{7}{|l|}{ Hip } \\
\hline $\mathrm{R}$ & 1.3 & 0.1 & 7.8 & 1.4 & 0.1 & 6.9 \\
\hline $\mathrm{L}$ & 1.3 & 0.1 & 8.6 & 1.4 & 0.1 & 5.2 \\
\hline \multicolumn{7}{|c|}{ Knee } \\
\hline $\mathrm{R}$ & 0.5 & 0.0 & 8.7 & 0.5 & 0.0 & 8.8 \\
\hline $\mathrm{L}$ & 0.5 & 0.0 & 6.7 & 0.5 & 0.0 & 7.0 \\
\hline
\end{tabular}

No significant differences were found between right and left sides. Males' and females' values were reported separately to account for differences found in volume for each individual muscle

vs total volume was found quasi-invariant for asymptomatic young adults.

A reduced set of two (respectively, five) segmented slices, well chosen, can be used to compute muscular volume with less than $14 \%$ of error (respectively, $11 \%$ ) (Fig. 2).

This work comes with limitations. First, only 23 subjects were included in the study; however, as they were all aged between 18 and 24 years old, and as they all come from the same environment (medical students), the variability in their muscular system should be low. The small age range was an objective to better characterize the young asymptomatic population; however, further studies should quantify age-related changes by recruiting volunteers from different age groups. A second limitation is the focus made on the characterization of the muscles' geometry, not considering the muscle quality, measured by the fat infiltration, for example, that remains an important parameter to describe the muscular system. Fat infiltration can be evaluated from MRI images acquired with the Dixon method [24]; this was the case in our study and associated data are currently under analysis. A third limitation is the consideration of the anatomical cross-sectional area and not the physiological one: pennation angles of muscles were not considered as only axial slices were studied. Also, some muscles were grouped because of border's lack of visibility. Other studies reported this issue particularly considering the border between the vastus lateralis and vastus intermedius [2] suggesting to group the two muscles together because of frequent fusion in young adults. Similar grouping was made to build up the adductor group, erector spinae group and iliopsoas group. While the last group is widely considered as such in the literature [11,22, 32], grouping muscles comes from the difficulty to identify proper border between muscles of this group; this difficulty is enhanced here by the inclusion of young healthy students presenting little fat between aponeurosis of different muscles [2]. This study did not include the small external hip rotators as choice was made to consider muscles frequently used in the sagittal postural maintenance as part of a wider project. These small muscles should, however, be included in a future finer study. It must be kept in mind, however, that grouping muscles will reduce the ability to quantify precisely these muscles' characteristics and, therefore, to provide basic values for comparison with other populations. Nevertheless, this study's objective was to provide a first global database for these muscles, and a clinical-user-friendly tool to estimate global muscular group's volume and estimate, quantitatively, muscular changes. The model using reduced set of MRI segmented slices has been built on right-side data of subjects. The equations of the model have been applied on the left side and resulted in similar RMS errors (less than $1 \%$ difference), except for the spine flexors $(13.5 \%$ for the left side vs $5.7 \%$ for the right side).

With these points in mind, the first objective of this study was to report reference values for spinopelvic muscles' geometry, for young asymptomatic subjects, as few studies in the literature reported some of these values. Considering the cross-sectional area (CSA), our values are greater than the ones reported by Rasch et al. [31] but of the same order of magnitude; this can be due to the difference in the population studied; we included young asymptomatic subjects, whereas their data come from the healthy limb of people planned for unilateral total hip 

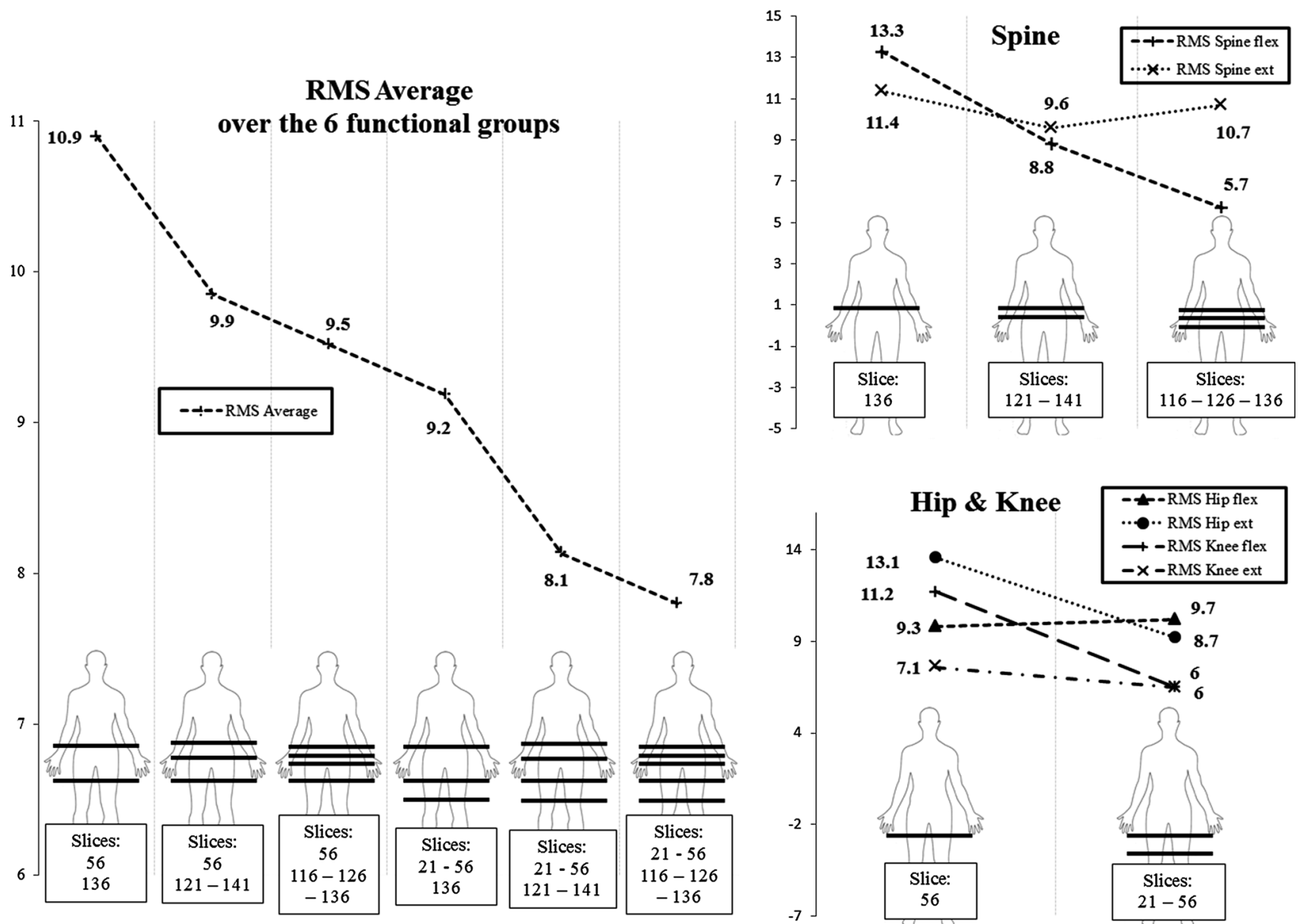

Fig. 2 RMS (root mean square) error for each functional group and on average over the six groups (RMS Average), for the different slices combinations chosen

Table 4 For each muscular group, coefficients of the predictors in column. Equation to predict the muscular volume of a functional group using slices numbering as detailed in Fig. 2 (Volume in $\mathrm{cm}^{3}$; Area in $\mathrm{cm}^{2}$; Constant in $\mathrm{cm}^{3}$; A, B in cm): Volume $=$ Constant $\times 1+\mathrm{A} \times$ Area_slice $21+$ B $\times$ Area_slice 56

\begin{tabular}{|c|c|c|c|c|}
\cline { 2 - 5 } \multicolumn{1}{c|}{} & \multicolumn{2}{c|}{ Hip } & \multicolumn{2}{c|}{ Knee } \\
\cline { 2 - 5 } \multicolumn{1}{c|}{} & Flex & Ext & Flex & Ext \\
\hline Constant & -191.9 & -73.0 & -193.1 & -294.8 \\
\hline A & 40.2 & 36.6 & 21.6 & 12.6 \\
\hline B & 33.4 & 33.4 & 18.2 & 22.5 \\
\hline
\end{tabular}

Area_slice_N corresponds to the sum of the areas of the muscles labeled in the functional group studied, on the slice $\mathrm{N}$ (in $\mathrm{cm}^{2}$ )

replacement (Table 2). Another reason for the difference observed can be that we reported the maximal CSA, contrary to Rasch et al. reporting CSA at the distal femoral level [31]. To our knowledge, no values were reported for the length of these muscles from axial images. The volume ratio, in percentage of total volume, was found similar to the values reported by Südhoff et al. [35] for the lower limb's muscles. We also reported an invariance of this volume ratio between subjects (SD less than $1.2 \%$ ) (Table 1). This parameter would be particularly interesting when studying altered muscles of elders or patients. 
Table 5 For each muscular group, coefficients of the predictors in column. Equation to predict the muscular volume of a functional group using slices numbering as detailed in Fig. 2: Volume $=$ Constant $\times$ $1+\mathrm{A} \times$ Femoral_Length $+\mathrm{B} \times$ Area_slice $116+\mathrm{C} \times$ Area_slice $126+\mathrm{D} \times$ Area_slice 136

\begin{tabular}{|c|c|c|}
\cline { 2 - 3 } \multicolumn{1}{c|}{} & \multicolumn{2}{c|}{ Spine } \\
\cline { 2 - 3 } \multicolumn{1}{c|}{} & Flex & Ext \\
\hline Constant & -465.6 & -24.4 \\
\hline A & 11.3 & 0 \\
\hline B & 8.0 & 5.5 \\
\hline C & -0.8 & 2.5 \\
\hline D & 14.9 & 12.1 \\
\hline
\end{tabular}

Area_slice_N corresponds to the sum of the areas of the muscles labeled in the functional group studied, on the slice $\mathrm{N}$ (in $\mathrm{cm}^{2}$ ). Volume in $\mathrm{cm}^{3}$; Constant in $\mathrm{cm}^{3}$; Femoral_Length in $\mathrm{cm}$; $\mathrm{A}$ in $\mathrm{cm}^{2} ; \mathrm{B}, \mathrm{C}$, $\mathrm{D}$ in $\mathrm{cm}$

Considering muscular volume, comparison can be made with some previous studies from the literature $[2,4,13$, 22]; overall, our findings are in line with these results. Looking into more details to the iliopsoas, for the men, our findings are greater than those of Lube et al. [22] and Handsfield et al. [13]: $515 \mathrm{~cm}^{3}$ vs between 442 and $452 \mathrm{~cm}^{3}$ for these studies. For the women, our results are greater $\left(291 \mathrm{~cm}^{3}\right)$ than Lube's $\left(252\right.$ to $\left.268 \mathrm{~cm}^{3}\right)$ [22] but lower than Handsfield's $\left(452 \mathrm{~cm}^{3}\right)$ [13]. Differences can be due to differences in the population studied (higher BMI, wider age range, etc...): for example, Handsfield et al. reported values for 24 healthy participants (with only 8 females) [13], and Lube et al.'s study [22] included only 3 females and 3 males. All these comments could also apply to differences observed with these studies for the adductor group and biceps femoris. For the latter, Lube et al. already reported large variation of its volume across different populations; difference in the participants of each study could explain these differences, maximal difference of $47 \mathrm{~cm}^{3}$ for men with Lube's data [22]. Moal et al. [24] reported muscular volume for the same functional groups as this study did, but including patients with adult spinal deformities: overall, the muscles studied presented a greater volume in the young asymptomatic group of this study. This agrees with the general and documented knowledge of sarcopenia (loss of skeletal mass) occurring with aging $[1,10,26]$ as well as muscular degradation occurring with spinal pathologies [12, 29].

No major asymmetry was reported between right and left volumes of individual muscles. In comparison, previous studies have reported a limited role of multifidus volume asymmetry in prediction of low back pain syndrome [7]. Fortin et al. reported a threshold of $10 \%$ of asymmetry to be the limit before abnormality [9]: the asymmetries found in this study were less than $12 \%$ which confirm our population as a reference group, in addition to its young age.

Considering the muscular groups' volumes, sex differences were found (Table 3).

As for the shape factor, the methodology described here was based on the study of Mersmann et al. [23] on lower leg muscles. Still, we found similar variability of the shape factor as they did: maximum SD found here $=0.04$ vs 0.04 (untrained subjects) and 0.05 (endurance athletes) as reported by Mersmann et al. [23] (Table 2). One can note that the maximal variability between subjects for the shape factor was reported here for the quadratus lumborum; this can be explained by its short length (Table 1); as it is visible on few slices with an irregular shape along the proximal-distal axis, it is difficult to characterize it by the same equation for all subjects. The use of this shape factor appears as adapted to compute muscle volume for most muscles (RMS $<10 \%$ ), but is not adapted for short muscles: gluteus minimus $(\mathrm{RMS}=11.9 \%)$, quadratus lumborum $(\mathrm{RMS}=17.7 \%)($ Table 2$)$.

Among all models studied (from two to five slices), the two-slices model provided a gross estimation of muscular volume (Fig. 2: average RMS $=10.9 \%$ ). The five-slices model is a possible compromise between accuracy and analysis time in a routine environment, while the whole 3D model could be more appropriate for research, particularly when considering the spine extensors (RMS $<8 \%$ for the average over the six functional groups (Fig. 2)). This model uses a combination of two "distal slices" and three "proximal slices". Two "distal slices" are required: one near the distal end of the femur (slice 21) to estimate volume of muscles (semimembranosus and biceps femoris breve for example); one mid-way on the diaphysis (slice 56) to better evaluate the great thigh muscles (adductor, vastii, rectus femoris, for example). The three "proximal" slices (slices 116, 126 and 136) are located between the acetabulum and T12 to estimate the volume of spine flexors and extensors: these slices are close to each other (10 slices apart) to focus on an area with segmentation for all the three muscles of interest (iliopsoas, erector spinae and quadratus lumborum) but also to estimate volume of a small and changing muscle in shape: the quadratus lumborum. Also, the model is not sensitive to the exact position of the slice suggested in the model; using a slice positioned five slices above or below, changes the averaged RMS by $1.5 \%$ maximum. Therefore, if validated on other populations, this method could be implemented in clinical routine for muscle characterization.

The two methods presented to compute muscular volume from little information are of same accuracy (RMS around $10 \%$ for both), but differ in their implementation: if the shape factor is useful for an individual muscle, the five-slices model can compute volume of muscles' group. 
Both, however, gain time during analysis of MRI images (reconstruction time fairly reduced: five slices segmented vs more than 120 slices for total 3D reconstruction).

Different levels of analysis may be needed for characterizing muscular geometry; in clinical routine, a rapid method could provide a global insight of the patients' muscles, while in research, a longer method can be considered to obtain a finer analysis. If the DPSO method is the current method providing the most relevant estimation of each individual muscle's geometry, a new method has been proposed here for use in a clinical environment: it is less time-consuming and provides, still, a good estimation of functional groups' muscular volumes.

The current model appears promising for clinical routine to quantify muscular volume of functional groups. This model still needs to be validated on other populations (older adults, patients), and when validated, could provide a clinical-user-friendly tool to determine quantitatively the muscular degradation of patients/volunteers.

In conclusion, our study provided a database for geometrical parameters of spinopelvic muscles for young asymptomatic adults. A new model computing the functional groups' muscular volume has been proposed and appears promising in estimating muscular volume of volunteers/patients.

Acknowledgments The authors thank the ParisTech BiomecAM chair program on subject-specific musculoskeletal modelling, and in particular COVEA and Société Générale. The authors thank the support received from the Anatomy association from Nice, France (Association d'Anatomie Niçoise). The authors also thank the support received from the Fulbright Program as a Fulbright PhD scholarship.

\section{References}

1. Ahmed MS, Matsumura B, Cristian A (2005) Age-related changes in muscles and joints. Phys Med Rehabil Clin N Am 16:19-39. doi:10.1016/j.pmr.2004.06.017

2. Barnouin Y, Butler-Browne G, Voit T, Reversat D, Azzabou N, Leroux G, Behin A, McPhee JS, Carlier PG, Hogrel J-Y (2014) Manual segmentation of individual muscles of the quadriceps femoris using MRI: a reappraisal. J Magn Reson Imaging 40:239-247. doi:10.1002/jmri.24370

3. Barrey C, Roussouly P, Le Huec J-C, D'Acunzi G, Perrin G (2013) Compensatory mechanisms contributing to keep the sagittal balance of the spine. Eur Spine J 22:S834-S841. doi:10. 1007/s00586-013-3030-z

4. Belavý DL, Miokovic T, Rittweger J, Felsenberg D (2011) Estimation of changes in volume of individual lower-limb muscles using magnetic resonance imaging (during bed-rest). Physiol Meas 32:35-50. doi:10.1088/0967-3334/32/1/003

5. Crawford RJ, Filli L, Elliott JM, Nanz D, Fischer MA, Marcon M, Ulbrich EJ (2016) Age- and level-dependence of fatty infiltration in lumbar paravertebral muscles of healthy volunteers. Am J Neuroradiol 37:742-748. doi:10.3174/ajnr.A4596

6. Danneels LA, Vanderstraeten GG, Cambier DC, Witvrouw EE, De Cuyper HJ (2000) CT imaging of trunk muscles in chronic low back pain patients and healthy control subjects. Eur Spine J 9:266-272. doi:10.1007/s005860000190

7. Fortin M, Gibbons LE, Videman T, Battié MC (2015) Do variations in paraspinal muscle morphology and composition predict low back pain in men? Scand J Med Sci Sport 25:880-887. doi:10.1111/sms.12301

8. Fortin M, Lazáry À, Varga PP, McCall I, Battié MC (2016) Paraspinal muscle asymmetry and fat infiltration in patients with symptomatic disc herniation. Eur Spine J. doi:10.1007/s00586016-4503-7

9. Fortin M, Videman T, Gibbons LE, Battié MC (2014) Paraspinal muscle morphology and composition: a 15-year longitudinal magnetic resonance imaging study. Med Sci Sports Exerc 46:893-901. doi:10.1249/MSS.0000000000000179

10. Frontera WR, Hughes VA, Fielding RA, Fiatarone MA, Evans WJ, Roubenoff R (2000) Aging of skeletal muscle: a 12-year longitudinal study. J Appl Physiol 88:1321-1326

11. Ghiasi MS, Arjmand N, Shirazi-Adl A, Farahmand F, Hashemi H, Bagheri S, Valizadeh M (2016) Cross-sectional area of human trunk paraspinal muscles before and after posterior lumbar surgery using magnetic resonance imaging. Eur Spine J 25:774-782. doi:10.1007/s00586-015-4014-y

12. Gildea JE, Hides JA, Hodges PW (2013) Size and symmetry of trunk muscles in ballet dancers with and without low back pain. J Orthop Sport Phys Ther 43:525-533. doi:10.2519/jospt.2013.4523

13. Handsfield GG, Meyer CH, Hart JM, Abel MF, Blemker SS (2014) Relationships of 35 lower limb muscles to height and body mass quantified using MRI. J Biomech 47:631-638. doi:10.1016/ j.jbiomech.2013.12.002

14. Hausselle J, Assi A, El Helou A, Jolivet E, Pillet H, Dion E, Bonneau D, Skalli W (2014) Subject-specific musculoskeletal model of the lower limb in a lying and standing position. Comput Methods Biomech Biomed Eng 17:480-487

15. Jolivet E, Daguet E, Pomero V, Bonneau D, Laredo JD, Skalli W (2008) Volumic patient-specific reconstruction of muscular system based on a reduced dataset of medical images. Comput Methods Biomech Biomed Engin 11:281-290. doi:10.1080/ 10255840801959479

16. Jolivet E, Dion E, Rouch P, Dubois G, Charrier R, Payan C, Skalli W (2014) Skeletal muscle segmentation from MRI dataset using a model-based approach. Comput Methods Biomech Biomed Eng Imaging Vis 2:138-145. doi:10.1080/21681163. 2013.855146

17. Kjaer P, Bendix T, Sorensen JS, Korsholm L, Leboeuf-yde C (2007) Are MRI-defined fat infiltrations in the multifidus muscles associated with low back pain ? BioMed Cent Med. doi:10.1186/ 1741-7015-5-2

18. Lee JC, Cha J-G, Kim Y, Kim Y-I, Shin B-J (2008) Quantitative analysis of back muscle degeneration in the patients with the degenerative lumbar flat back using a digital image analysis: comparison with the normal controls. Spine (Phila Pa 1976) 33:318-325. doi:10.1097/BRS.0b013e318162458f

19. Lee MK, Le NS, Fang AC, Koh MTH (2009) Measurement of body segment parameters using dual energy X-ray absorptiometry and three-dimensional geometry: an application in gait analysis. J Biomech 42:217-222. doi:10.1016/j.jbiomech.2008.10.036

20. Li F, Laville A, Bonneau D, Laporte S, Skalli W (2014) Study on cervical muscle volume by means of three-dimensional reconstruction. J Magn Reson Imaging 39:1411-1416. doi:10.1002/ jmri.24326

21. Lilliefors HW (1967) On the Kolmogorov-Smirnov Test for normality with mean and variance. J Am Stat Assoc 62:399-402

22. Lube J, Cotofana S, Bechmann I, Milani TL, Özkurtul O, Sakai T, Steinke H, Hammer N (2016) Reference data on muscle volumes of healthy human pelvis and lower extremity muscles: an 
in vivo magnetic resonance imaging feasibility study. Surg Radiol Anat 38:97-106. doi:10.1007/s00276-015-1526-4

23. Mersmann F, Bohm S, Schroll A, Arampatzis A (2014) Validation of a simplified method for muscle volume assessment. J Biomech 47:1348-1352. doi:10.1016/j.jbiomech.2014.02.007

24. Moal B, Bronsard N, Raya JG, Vital J-M, Schwab F, Lafage V (2015) Volume and fat infiltration of spino-pelvic musculature in adults with spinal deformity. World J Orthop 6:727-737. doi:10. 5312/wjo.v6.i9.727

25. Moal B, Raya JG, Jolivet E, Schwab F, Blondel B, Lafage V, Skalli W (2014) Validation of 3D spino-pelvic muscle reconstructions based on dedicated MRI sequences for fat-water quantification. Innov Res Biomed Eng 35:119-127. doi:10.1016/ j.irbm.2013.12.011

26. Narici MV, Maganaris CN, Reeves ND, Capodaglio P (2003) Effect of aging on human muscle architecture. J Appl Physiol 95:2229-2234. doi:10.1152/japplphysiol.00433.2003

27. Niemeläinen R, Briand MM, Battié MC (2011) Substantial asymmetry in paraspinal muscle cross-sectional area in healthy adults questions its value as a marker of low back pain and pathology. Spine (Phila Pa 1976) 36:2152-2157

28. Nuzzo JL, Mayer JM (2013) Body mass normalisation for ultrasound measurements of lumbar multifidus and abdominal muscle size. Man Ther 18:237-242. doi:10.1016/j.math.2012.10. 011

29. Parkkola R, Rytökoski U, Kormano M (1993) Magnetic resonance imaging of the discs and trunk muscles in patients with chronic low back pain and healthy control subjects. Spine 18:830-836. doi:10.1097/00007632-199306000-00004

30. Pezolato A, de Vasconcelos EE, Defino HL, Nogueira-Barbosa MH (2012) Fat infiltration in the lumbar multifidus and erector spinae muscles in subjects with sway-back posture. Eur Spine J 21:2158-2164. doi:10.1007/s00586-012-2286-z
31. Rasch A, Byström AH, Dalen N, Berg HE (2007) Reduced muscle radiological density, cross- sectional area, and strength of major hip and knee muscles in 22 patients with hip osteoarthritis. Acta Med Iran 78:505-510. doi:10.1080/17453670710014158

32. Sanchis-Moysi J, Idoate F, Izquierdo M, Calbet JAL, Dorado C (2011) Iliopsoas and gluteal muscles are asymmetric in tennis players but not in soccer players. PLoS One 6:6-15. doi:10.1371/ journal.pone. 0022858

33. Savage RA, Millerchip R, Whitehouse GH, Edwards RHT (1991) Lumbar muscularity and its relationship with age, occupation and low back pain. Eur J Appl Physiol Occup Physiol 63:265-268. doi:10.1007/BF00233859

34. Skeie EJ, Borge JA, Leboeuf-Yde C, Bolton J, Wedderkopp N (2015) Reliability of diagnostic ultrasound in measuring the multifidus muscle. Chiropr Man Therap 23:1-12. doi:10.1186/ s12998-015-0059-6

35. Südhoff I, de Guise JA, Nordez A, Jolivet E, Bonneau D, Khoury V, Skalli W (2009) 3D-patient-specific geometry of the muscles involved in knee motion from selected MRI images. Med Biol Eng Comput 47:579-587. doi:10.1007/s11517-009-0466-8

36. Takahashi K, Takahashi HE, Nakadaira H, Yamamoto M (2006) Different changes of quantity due to aging in the psoas major and quadriceps femoris muscles in women. J Musculoskelet Neuronal Interact 6:201-205

37. Takayama K, Kita T, Nakamura H, Kanematsu F, Yasunami T, Sakanaka H, Yamano Y (2016) A new predictive index for lumbar paraspinal muscle degeneration associated with aging. Spine (Phila Pa 1976) 41:E84-90. doi:10.1017/CBO9781107415324.004

38. Valentin S, Licka T, Elliott J (2015) Age and side-related morphometric MRI evaluation of trunk muscles in people without back pain. Man Ther 20:90-95. doi:10.1016/j.math.2014.07.007 